\title{
Ethics as Part of a New Regulation Scheme \\ Global Trends and European Specificities
}

\author{
BERNARD PERRET ${ }^{* *}$
}

\section{Ethik als Teil eines neuen Regulierungsparadigmas - Globale Trends und europäische Besonderheiten}

This paper analyses the development of economic and business ethics as an element of a new regulation scheme of the capitalist economy. It is argued that a more formal recourse to ethical justifications is becoming more indispensable due to a lesser relevance and/or efficiency of other mechanisms of social "embeddedness" of the economic system. The paper will then also analyse the specific influence of the European process on this evolution, showing that the constitutive logic of this process tends to promote individualistic values and procedural norms.

Keywords: Regulation, Embeddedness, Economic Change, European Unification Process

\section{Economic regulation, ethics and social science}

The keyword of this paper is 'regulation'. In this text, the concept of regulation refers mainly to the French Regulation Theory (Boyer/Sailard 2001). It is rarely defined, but we can accept the following definition of the theory as sufficiently clear:

"The aim of Regulation Theory is to identify the institutions necessary and sufficient to the sustainability of a capitalist economy and, then, analyse their dynamics within every institutional architecture observed in a given geographical area and time period." (Boyer 2003)

Of course, ethics is usually not considered as an institution (although it could be considered so, under certain aspects), but no one would deny that it is part of the social framework of economic activities. The benefit of including ethics into the regulation framework of economic activities is to allow renewed interpretations of its recent development. It makes clear that the ethical trend takes place in a defined political and ideological context related to structural changes in the socio-economic system dynamics and organization. I will illustrate this idea through two distinct topics:

The article has been subject to a double blind peer review process. Date of submission: 6th September, 2007; revisited version accepted for publication: 25th August, 2008.

Bernard Perret, Conseil général de l'écologie et du développement durable, Centre de recherche et d'information sur la démocratie et l'autonomie (CRIDA), 'Pièce 2751, Tour Pascal B, F-92055 Paris la Défense Cedex, France, e-mail: bernard.perret@developpement-durable.gouv.fr, fields of expertise: socio-economics, social theory, policy evaluation, social aspects of sustainable development. 
- economic change and its consequences at the global level, - the impact of the European political process.

Before developing these two points, let me begin with a brief consideration about the place of ethical questions in social science. In France, the questions discussed in this conference $^{1}$ are often addressed under the banner of economic sociology ${ }^{2}$. Economic sociology, or socio-economics, can be defined as the sociological study of economic phenomena. This program entails a critical attitude towards the utilitarian presuppositions of the dominant economic theory and also, at least in an implicit way, towards the economic system itself. It is a fact that French social science has not renounced to assume a critical role. It still assumes a part of denouncing function of Marxism even if most of its representatives do not really want to replace market economy by another system. As a philosophical system, Marxism is almost dead, but its critical stance is still active. On the other hand, the authors mentioned are influenced by the Durkheimian conception of sociology. For Durkheim, sociology is somehow in charge of social cohesion. The sociologist is less a critical analyst than a kind of therapist of social diseases.

This double inheritance encapsulates ethical and political concerns. Socio-economists are often politicized people: many of them would support the project of limiting the hold of market on society. As observed by Levesque et al. (1997), the major trends of both French and English speaking socio-economics adopt a critical approach towards the utilitarian presuppositions of neoclassical economics. Implicitly, this intellectual posture entails a political one. Although I am well aware of the objections it could provoke - notably, one could say that it mixes social analysis and value statements in an unclear way (Perret/Roustang 1993/2001) - it can be argued that the regulation of economic activity remains basically a political issue, and that social science should help to cope with this issue. For example, my book, Les nouvelles frontières de l'argent (Perret 1999) is about the social role of money and deals with the question of gratuity from a sociological and anthropological point of view, but from an explicit political and ethical perspective. Analyzing the mechanisms and consequences of the growing role of money as a mechanism of social exchange is important, because public policies may

1 "European Business and Economic Ethics: Diagnosis - Dialogue - Debate. Is There a European Business and Economic Ethics Approach?” international Conference organized by the Berlin Forum, in Heidelberg, Germany, September 6 - 8, 2007, supported by the Heidelberger Akademie der Wissenschaften.

2 I refer notably to Alain Caillé (the editor of the Revue du MAUSS - Mouvement anti-utilitariste en sciences sociales, Edition de la Découverte), (Caillé 2004) or to Jean-Louis Laville (2006) (who has promoted the notion of «Solidary Economy »). The most quoted « founding texts » of sociological economy are the book of Karl Polanyi (1985) The great transformation and the works of Durkheim (1893/2007) and Marcel Mauss (1990). One could also mention the American sociologist Daniel Bell (1996) (The cultural contradictions of capitalism), in spite of obvious differences of styles, methodology and ideological inspiration. These authors have in common that they analyse the relationships between the economic system and its cultural and social context from a critical perspective. At the international level, the main representative organization is the Society for the Advancement of Socio-Economics (SASE). 
contribute to increasing or reducing the domain within which money operates and/or its legitimacy as a way of rewarding social activities.

In apparent contradiction with this profession of faith, the rest of the paper explains why economic and business ethics is becoming less subordinated to politics and will probably play a greater role in the future in the regulation of the economic system.

\section{Economic change and its social and ideological consequences at global level}

Things are changing, even in France. The years 1980-2000 have been marked by a spectacular decline of Marxist ideas and, more broadly, by a decline of political evaluations to the benefit of moral considerations. It only recently (2004) became suitable for a fashionable philosopher to entitle a book "Le capitalisme est-il moral?" (Is capitalism moral?). Considering the ideological shift since 1968, the same author writes: "All was political, politics was all, as far as a good politics seemed to us the only necessary morals" (Comte-Sponville 2004: 18). Undoubtedly, this is no more the case, even if there are residues of this situation.

The irruption of John Rawls' ideas in the French political debate in the nineties has been a spectacular symptom of this new climate. The most important idea conveyed by Rawls' Theory of Justice (1971) is that there is room for a rational notion of social justice in a capitalist economy. This idea stands in contradiction to traditional left wing ideas which assume that social justice cannot be defined and discussed in a neutral way but only as a contentious issue of class struggle. ${ }^{3}$

These changes have cultural, political, and even geopolitical causes. The end of communism is undoubtedly an important causal factor, as well as the decline of religious institutions which have always efficiently promoted non-economic values. But the main factors are purely economical. The ethical mood can be explained by (1) globalization and the decline of public regulation, (2) a loss of teleological justification of economic order, (3) the growing importance of externalities, (4) the growing importance of reputation and (5) changes in the governance of firms.

\subsection{Globalization and the decline of public regulation}

In a globalized economy, nation states have lost much of their capacity to fix the rules of the economic game. Facing mass unemployment, they cannot fight it directly by creating public jobs or making firms keep their useless employees. The best they can do is to create conditions favorable to economic growth. The "disempowerment" of public actors in the economic sphere has led to a distinction between the "Common" (common good and common goods) and the "Public". For example, it is now well acknowledged that services of general interest should not necessarily be provided by public organizations. ties", when it became obvious that different major social objectives could conflict - notably that the objective of reducing wage inequalities could conflict the objective of reducing unemployment. 
Accordingly, the responsibilities of all social actors have to be redefined: the burden of implementing redistributive justice cannot be placed entirely upon public authorities' shoulders. Logically, private actors are compelled to occupy more space and to assume more responsibility, to consider themselves more directly accountable for social justice and social development. The development of business ethics is a direct consequence of this new understanding of firms' responsibilities.

Of course, this change has not gained the same assent in all European countries. Political cultures are more or less in harmony with the idea that private actors are coresponsible for the common good in the socio-economic sphere. It is well known that France is more attached than other countries to the idea of the State being accountable for social justice. But, even in France, the strength of economic realities has progressively imposed a new way of thinking.

\subsection{The loss of teleological justifications of the economic order}

The enlarged function of ethics can also be interpreted in the light of the weakening of teleological justifications of economic development. During the last two centuries, economic growth was strongly supported by the conviction that it was part of a global historical process leading humanity towards well-being and happiness. This credo was shared by Marxists, socialists and all those influenced by liberal economical thought. One the one hand, this belief provided a strong justification for all decisions made necessary by economic competition and technical progress, regardless of their social consequences. On the other hand, it was also part of the great historical narrative that gave - sometimes in a subliminal way - a quasi-religious meaning to all the social struggles.

This progressivist climate was not an arbitrary ideological mood: it was objectively supported by the fact that economic growth and social progress proved to be natural, even if often conflicting, allies. They were interlinked in such a way that they quite inevitably reinforced each other over a certain time, in spite of their apparent contradictions, if not thanks to these contradictions.

The Fordist model, as conceptualized by a set of French economists in the 1980's, shows very clearly the mechanisms behind this convergence in a particular historical context. It explains why this convergence has been so strong during the thirty years after World War II, and why it has progressively been destroyed. It suggests that the economic system has lost its dynamic social stability since the middle of the seventies.

The Fordist system can be understood as the mutual enforcement of a set of economic and social mechanisms. It can be characterized by the four following elements:

- A specific consumption pattern, characterized by the increasing consumption of standardized manufactured objects, liable to be produced in large series (cars, household electrical equipment etc.).

- Taylorism as the core model of industrial work organization, in keeping with the mentioned consumption pattern.

- The so-called Fordist social compromise implemented at the firm level through the "Fordist salary relationship", a key element of the Fordist system. 
- A Keynesian-interventionist state, whose policy, both in the economic field (Keynesian macro economic policies), and in the social field (minimum wage etc.) guaranteed the coherence of the system through a high and steady growth rate.

These four subsystems were synergetic, each one reinforcing and stabilizing the others.

During the last thirty years, the system progressively lost its coherence. Several factors of disturbance have been at work, weakening all four subsystems and their coherence:

- The evolution of the consumption pattern: Among other factors it can be demonstrated that growing social needs (health care, seniors care, education, security, culture and so on) are less easily incorporated in a steady growth cycle, because of their low productivity growth.

- Evolutions in work and management, post-Fordist management being less favorable to mass social integration through work.

- "Globalization", which disables the tools of national macroeconomic policies.

The crumbling of the Fordist coherence suitably explains the crisis of the Welfare State and of all the ideologies based on the belief in a natural concordance between economic development and social progress. Combined with the ecological crisis it renders the beneficial character of economic growth doubtful and weakens the teleological rationale of both economic decisions and social objections to these decisions. Hence, the moral justification of decisions to be taken in the economic field cannot be preempted any more by an overarching rationale - economic rationality or the socalled "sense of history".

\subsection{The growing importance of externalities}

I use the economic notion of externality in an extended sense here. I mean by externality an impact of economic activities which has no direct feedback on the system of constraints and incentives within which firms usually take their decisions.

A growing part of the social consequences of economic activity cannot be handled and mastered within the inner logic of the socio-economic game. Contrary to basic social issues such as wages or work conditions, they are not issues of social conflicts.

Today, important consequences of economic activities are not direct issues of the social game at the firm level. Economic powers have extended possibilities to take decisions - for example closing an industrial plant in a distant country - which have tangible social consequences but which are likely to provoke only ineffective protests. If one considers the ecological impact of economic activity - for example those related to the greenhouse effect, there is the same gap between a growing awareness of the problem's gravity and the weakness of the direct pressure put on economic actors by public institutions and social forces.

Less visible but also important are the "cultural contradictions of capitalism" pointed out in 1976 by the American sociologist Daniel Bell (1976). According to Bell, the main contradiction of post-industrial capitalism lies in the antinomy between the behavior and the values underlying mass consumption - hedonism, the apology of 
desire, the right to comfort and security - and the values underlying productive activities - effort, efficiency, the love of quality work, loyalty, and saving. This contradiction is diffuse, it is systemic; no stakeholder group, no social force is especially concerned. It has no chance to become a political issue.

The increase of the moral accountability of private actors stems from the fact that critical consequences of economic activities can no longer be addressed through current social or political feedback mechanisms. When economic actors become conscious of this lack of control, and of the lack of systemic stability which might result from this, they are forced to create self-control mechanisms based on personal motives inherited from their cultural background. They need to give themselves rules of conduct related to ethical principles.

\subsection{The growing importance of reputation}

Of course, ethical principles are not always invoked for mere idealistic reasons: they may also have a direct positive economic impact through reputation and trust. There is nothing new here: the economic value of morality and religion has been brilliantly illustrated by a famous text by Max Weber - the account of a train journey through the United-States, during which a man explained to him why it is necessary to belong to a religious community to make good business (Weber 2001).

In our modern post-industrial and "post-scarcity" economic world, reputation is more than ever a strategic asset. The main economic challenge is not to produce but to sell. Consumption behavior is more and more oriented towards satisfaction of desires, and desires are subject to the influence of ideals. If you do not really need an object, which is most often the case, you may not want to buy it from a producer whose behavior strongly conflicts with your values. The same applies to stock markets where investors are strongly influenced by the reputation of firms. The creation of social rating agencies in charge of assessing the social and environmental policies of firms is a clear symptom of this.

Both of these elements are related to the shift towards an immaterial economy, where symbolic assets gain more importance.

\subsection{Changes in firms governance}

The need for ethics is also related to the new corporate governance schemes. When the economic and managerial power over firms was exercised by individuals, the moral aspect of their decisions was just their own business: they were accountable only to their conscience. But with the economic power becoming more collective and impersonal, every important decision needs to be justified in a formal and rational way, taking into account all its possible consequences. It becomes necessary to formulate criteria for evaluating decisions under various dimensions, including ethical ones.

What used to be regulated by personal values needs to be formalized as a set of opposable norms that becomes part of governance schemes.

All these changes are in favor of rational ethical principles that would become part of the economic regulation framework. 


\section{The European case}

In a second part, I want to analyze the specific influence of the European unification process - in the context of these global trends - to see how it contributes to shaping the institutional and normative framework of economic activities in a specific direction.

For many French people, and not only left wing people, the true and only legitimate finality of the European unification process is to create a great unified economic and social space within which public interventions would find a new relevance and efficacy. They have not renounced to export at the European level a French conception of the centralized interventionist state. Europe, in other words, is thought of as a possible protection against the deregulating effects of economic globalization.

But, as we all know, the reality is very different. Europe has inherited contradictory conceptions of the state's role from which it is very difficult to derive a consensual doctrine that could legitimate hard policies.

\subsection{The constitutive logic of the European process}

When we speak of the European model, we have generally in mind a kind of average, middle of the road system, built with elements that we have in common. It is often argued that European socio-economic systems can be differentiated from most other systems by their attempt to conciliate market economy, a high degree of social protection and a culture of social dialog.

But, as soon as we leave these generalities and go into the details of our social regulation schemes, we see very different conceptions of rights and duties in the labor market i.e. and in the economic sphere at large.

The French sociologist Philippe d'Iribarne has shown this very clearly (D'Iribarne 2006). According to his comparative observations, what he calls the "logic of honor" is a key mechanism of motivation for French workers at any level of the social hierarchy, while German workers are more attached to the communitarian dimension of the firm, and English workers more sensible to the logic of contract. In spite of the growing interactions between the different national systems, they do not seem to loose their specificities. This has important consequences for the ruling of social systems: a lot of social questions will continue to be managed at the national level.

In fact, the direct social interventions of the European Union are quite marginal and will remain marginal for a long time. Social benefits for disadvantaged individuals are decided upon and distributed at the national level. The main constituents of European social policies are regional development policies (usually called structural funds). European social intervention is conceived of as a corrective intervention aiming at maintaining a territorial cohesion, favorable to economic growth and necessary for the acceptability of economic integration.

But the European social policy in a larger sense is not mainly built of programs and subsidies. More important is the fact that the construction of Europe has given birth to a new level of normativity. I want to argue that the new institutional and ideological setting which emerges at the European level is less a synthesis or a compromise than a new layer, a new level of norms that did not exist before and which is superimposed 
on the existing, mostly national, regulation schemes. As regards our subject matter the role of ethics as part of the regulation schemes - we shall notice that this new layer is constituted of a new kind of norms, somewhere between political, juridical and ethical norms. This analysis is in line with a political science theory known as the "cognitive approach of public policies", whose basic assumption is that public policies are not mere implementations of preexisting rationalities but the uncertain result of social interaction processes generating new ideas, representations and shared values.

Applied to the European community, this approach focuses on the inner logic of the European policy process, inviting to regard it as a structuring matrix of new political and ethical conceptions (Perret 2001). It could be related to a definition of the "Europeanization" process given by the political scientist Claudio Radaelli:

"Processes of construction, diffusion and institutionalization of formal and informal rules, procedures, policy paradigms, styles, 'ways on doing things' and shared beliefs and norms which are first defined and consolidated in the making of EU public policy and politics and then incorporated in the logic of domestic discourse, identities, political structures and public policies.” (Radaelli 2007: 110 quoted by Palier/Surel 2007: 37)

This constitutive process, of course, is very complex, and even rather chaotic, influenced by purely contingent political circumstances. Notwithstanding, it seems possible to identify a set of permanent factors that probably contribute to shape the European social system.

As concerns our subject, the European process appears to convey the following structuring factors:

- First, the European project has always been conceived of primarily as an economic project whose overarching finality is the economic prosperity of European people. European policies are more or less related and subordinated to economic goals. The issue of territorial and social cohesion is only a secondary issue, emerging from the self-evident fact that economic integration provokes growing territorial and social disparities. One might even say that social and ethical principles promoted at the European level bear the mimetic influence of economic logic, in the sense that they tend to be formulated exclusively from the point of view of individual rights and utility.

- The European commission is confronted with a deficit of home made expertise. It needs to compensate this deficiency and reinforce its position against national governments by an extended recourse to non-governmental expertise. "In search of expertise and legitimacy, the Commission has ever since fostered the dialog with expert groups and various stakeholder groups" (Woll 2007: 162). On the other hand, non-governmental organizations, stakeholder groups and minorities have an obvious interest in cooperating with European institutions to reinforce their credibility at the national level. 
- The cognitive conditions of European policy making must be taken into account. The elaboration of common policy principles must face the communication difficulties arising among people speaking a dozen different languages. This gives another advantage to clear-cut notions with the least ambiguities and with the least context dependencies, based on universal ethical principles.

Finally, and not surprisingly, the following individualistic and procedural values emerge as typical for the European community building process. Firstly, these values are what could be named methodological standards:

- Open discussion, explicit confrontation of all interests and principles, in line with Jürgen Habermas' ethics of discussion (Habermas 2003),

- the obligation to give voice to all the stakeholders in the policy process,

- the systematic use of regulation tools such as rating, evaluation, benchmarking, based upon a strong cognitive creed: coordination should be based upon clear and sharable information - able to produce a consensus pressure -, rather than upon authoritative constraints.

At a more substantial level, a set of consensual ethical values tend inevitably to be promoted:

- Individual autonomy as an overarching social objective. Social interventions aim at producing individual freedom - in the extended sense given by Amartya Sen (2000) through his theory of capabilities ("not only freedom from need, but also freedom to act"),

- a "non discrimination principle", implying the recognition of the rights of minorities (see for example the European charter for regional and minority languages), but also equal rights of men and women etc.,

- a social inclusion principle, according to which social interventions should aim at making actually everybody belong to and participate in society,

- an equity principle, in the sense given by John Rawls, according to which social benefits should aim at improving the relative situation of poorer people. This principle can be understood as implying compensatory mechanisms in favor of poorest areas and populations. It has been implemented at a large scale through regional policy (structural funds).

Finally, the underlying logic of these principles can be summarized by the term "generality". European Union needs to transcend the diversity of national social models with methodological and substantial requirements that stand at a high level of generality. Not surprisingly, these requirements are largely permeated by ideas and theories developed in the field of economic ethics.

\section{Conclusive remarks}

In conclusion, one may ask if this emerging socio-economic regulation scheme is "sustainable", in the sense that it could provide the conditions for a lasting positive relation between economic growth, social cohesion, and the progress of democracy and morality. Introducing the question of sustainability here may seem a bit artificial but the fact is that the notion of regulation is tightly related to the question of sustain- 
ability. Generally speaking, the aim of a regulation device is to provide long-term stability, by making a system able to react aptly to internal disequilibria or external perturbations.

Anyway, one may have doubts about the sustainability of our socio-economic system, for several reasons:

First, what we may call the new dominant social ideology promotes an individualistic notion of social rights at the expense of the embeddedness of solidarity in social mediations, like unions, associations etc. Social actors are reduced to their double role of workers and consumers. The role of collective action and solidarity tends to be minimized, if not ignored. Of course, trade unions are invited to give voice at the European level, but they have no real weight compared to the role they played at the national level in the building of social systems.

- Related to this, education is virtually reduced to its function of producing human capital. More generally, the non-economic aspects of social integration (culture, participation, quality of life within and without the work sphere), tends to be subordinated to economic goals.

- More widely, European policies actively contribute to the "monetarization" of society, that is, the growing role of money and market logic in social life.

- Of course, one may ask why such an evolution should be denounced. It is not the place here to argue at length about that. It seems sufficient to observe that monetarization phenomena mostly appear to be destructive of social capital: they tend to erode social networks, trust and norms of reciprocity.

- From a more philosophical point of view, one may observe that ethics is always related to global value judgments about social affairs. If ethics is not encapsulated in a wider system of meaning anymore, it runs the risk of becoming subordinated to the economic logic.

As a conclusion, another point could be introduced: it could be that the invading issue of sustainable development will have a feedback effect on European values. If the European Union wants to address the issue of sustainability through its policies, it will have to take into account social sustainability and the corrosive effects of monetarization on culture and social cohesion more seriously. It will force us to call up for principles of ethics and rationality which take into consideration the values of societies as common worlds of meaning, shaped by institutions deeply rooted in national histories and religious traditions. The utopia of a Europe of utilitarian individuals has little future. 


\section{References}

Bell, D. (1976): The Cultural Contradictions of Capitalism, New York: Harper Collins Publishers.

Boyer, R (2003): Les institutions dans la théorie de la régulation, in: Revue du CEPREMAP $\mathrm{N}^{\circ}$ 2003-08.

Boyer, R./ Sailard, Y. (2001): Regulation Theory: The State of the Art, London: Routledge.

Caillé, A. (2004): Dé-penser l'économique: Contre le fatalisme, Paris: La Découverte.

Comte-Sponville, A. (2004): Le capitalisme est-il moral? Paris : Livre de poche.

D’rribarne, P. (2006): L'étrangeté française, Paris: Seuil.

Durkheim, E. (1893/2007): La division du travail social, Paris, PUF.

Habermas, J. (2003): The Theory of Communicative Action, Boston: Beacon Press.

Laville, J.-L./ Catani, A.-D. (2006): Dictionnaire de l'autre économie, Paris: Folio.

Lévesque, B./ Bourque, G. L./ Forgues, É. (1997): La sociologie économique de langue française: originalité et diversité des approches, in: Cahiers internationaux de sociologie, (103), 265-294, Paris: Les Presses universitaires de France.

Mauss, M. (1990): The Gift: The Form and Reason for Exchange in Archaic Societies, New York u. a.: W W Norton \& Co In.

Palier, B./ Surel, Y. (2007) (Eds.): L'Europe en action, l'européanisation dans une perspective comparée, Paris: L'Harmattan.

Perret, B. (1999): Les nouvelles frontières de l'argent, Paris : Editions du Seuil.

Perret, B. (2001): Connaissance sociale et gouvernance, les promesses de l'évaluation, in: De Schutter, O./ Lebessis, N./ Paterson, J. (Eds.): La gouvernance dans l'Union européenne, les cahiers de la cellule de prospective, Bruxelles: Office des publications de la Commission européenne.

Perret, B./Roustang, G. (1993/2001): L'économie contre la société, Paris: Editions du Seuil.

Polanyi, K. (1985): The Great Transformation, Boston: Beacon Press.

Radaelli, C. (2007): The Domestic Impact of European Union Public Policies: Notes on Concepts, Methods, and the Challenge of Empirical Research, in: Politique européenne, $\mathrm{n}^{\circ} 5$.

Rawls, J. (1971/1999): A Theory of Justice, Cambridge, Mass.: Belknap Press.

Sen, A. (2000): Development as Freedom, New York: Anchor Books.

Weber, M. (2001): The Protestant Ethic and the Spirit of Capitalism, London: Routledge.

Woll, S.-S. (2007): L'européanisation et les acteurs non étatiques, in: Palier , B./ Surel, Y. (Eds.): L'Europe en action, l'européanisation dans une perspective comparée, Paris: L'Harmattan. 